\title{
Nociceptive and Neuropathic Pain Qualities in Men and Women with Acute Coronary Syndromes: A Complex Pain Presentation
}

\author{
Sheila 0'Keefe-McCarthy ${ }^{1}$, Michael McGillion' ${ }^{2}$, Charles J. Victor ${ }^{3}$, Sheila Rizza ${ }^{4}$, \\ Judith McFetridge-Durdle ${ }^{5}$ \\ ${ }^{1}$ Brock University, St. Catharines, Ontario, Canada \\ ${ }^{2}$ Heart and Stroke Foundation/Michael G. De Groote Endowed Chair in Cardiovascular Nursing Research, \\ School of Nursing, Faculty of Health Sciences, Hamilton, Ontario, Canada \\ ${ }^{3}$ University of Toronto, Toronto, Ontario, Canada \\ ${ }^{4}$ Nurse Practitioner Heart Failure Clinic, Trillium Health Partners-Credit Valley Site, Mississauga, Ontario, Canada \\ ${ }^{5}$ Florida State University College of Nursing, Tallahassee, Florida, US \\ Email: *sokeefemccarthy@brocku.ca
}

How to cite this paper: O'Keefe-McCarthy, S., McGillion, M., Victor, C.J., Rizza, S. and McFetridge-Durdle, J. (2017) Nociceptive and Neuropathic Pain Qualities in Men and Women with Acute Coronary Syndromes: A Complex Pain Presentation. Open Journal of Nursing, 7, 331-344.

https://doi.org/10.4236/ojn.2017.73027

Received: December 21, 2016

Accepted: March 11, 2017

Published: March 14, 2017

Copyright $\odot 2017$ by authors and Scientific Research Publishing Inc. This work is licensed under the Creative Commons Attribution International License (CC BY 4.0).

http://creativecommons.org/licenses/by/4.0/

\begin{abstract}
Background: Cardiac pain arising from acute coronary syndrome (ACS) is a multi-factorial phenomenon. Historically, episodes of cardiac pain have been captured using a one-dimensional numeric pain rating scale. Lacking in clinical practice are acute pain assessments that employ a comprehensive evaluation of an emergent ACS episode. Aim: To examine the sensory-discriminative, motivational-affective and cognitive-evaluative dimensions of ACS-related pain. Methods: A descriptive-correlational, repeated-measure design was used to collect data on 121 ACS patients of their cardiac pain intensity. The (numeric rating scale-NRS 0-10 scale) measured chest pain "Now" and "Worst pain in the previous 2 hours over 8 hours" and the McGill Pain Questionnaire Short-Form (MPQ-SF) measured pain at 4 hours. Results: Mean age was $67.6 \pm 13,50 \%$ were male, $60 \%$ had unstable angina and $40 \%$ had Non-ST-elevation myocardial infarction. Cardiac pain intensity scores remained in the mild range from $1.1 \pm$ 2.2 to $2.4 \pm 2.7$. MPQ-SF: $66 \%$ described pain as distressing and $26 \%$ reported pain was horrible or excruciating. Participants described ACS pain quality as acute injury (nociceptive pain: heavy, cramping, stabbing), as nerve damage (neuropathic: gnawing, hot-burning, shooting) and as a mixture of acute and chronic pain qualities (aching, tender and throbbing). Conclusions: Patients reported both nociceptive and neuropathic cardiac pain. It is unclear if pain perceptions are due to: i) pathophysiology of clot formation, ii) occurrence of a first or repeated ACS episode, or iii) complex co-morbidities. Pain arising from ACS requires an understanding of the interplay of ischemic, metabolic and
\end{abstract}


neuropathophysiological mechanisms that contribute to complex cardiac pain experiences.

\section{Keywords}

Acute Coronary Syndromes, Nociceptive Pain, Neuropathic Pain, Pain Descriptors, Emergency Department

\section{Introduction}

Complex cardiac pain presentations are problematic for patients to recognise and for clinicians to differentially diagnose as an acute coronary syndrome (ACS). "Excruciating, debilitating, throbbing, pressing, sickening; an aching kind of deep pain" have been used to describe acute chest pain experienced by individuals suffering an anginal episode or a seminal heart attack [1]. Cardiac-related pain arising from narrowed or blocked heart arteries (coronary artery disease [CAD]), resulting in myocardial ischemia, is individual and varies within a spectrum of unique symptom presentations. As is with other types of pain, cardiac pain is subjective and complex in nature and encompasses sensory-discriminative, motivational-affective, and cognitive-evaluative components [2]. Specific to the individual, these components are interconnected and sub-served by certain areas in the brain (i.e., spinal cord, reticular, frontal, cortical areas), which in turn, add to the overall patient experience and perception of cardiac pain [3] [4] [5] [6].

Current understanding of myocardial ischemia and the individual perception of cardiac pain has been informed by pain science and observations from clinical research and practice [1] [3] [4] [5] [6] [7]. Myocardial ischemia results from the development of atherosclerotic plaque build up that blocks blood flow through the epicardial arteries, compromising supply of rich oxygenated, nutrient saturated blood to the heart [8] [9]. At the tissue level, lack of blood supply triggers activation of the sympathetic and vagal afferent nociceptive pain fibres [8] [9]. The individual experience of cardiac pain is complicated and relates to the cumulative effect of myocardial oxygen supply and demand imbalance, the pain mechanisms involved in the neuro-modulation of painful stimuli at the levels of the neuroaxis, peripheral nerves, spinal cord and brain [7] and changes in neuro-plasticity that occur at the peripheral and central levels resulting in central sensitization [4] [5] [6] [10].

Historically, chest pain intensity in clinical practice has been measured with one-dimensional tools such as the numeric pain rating scale (NRS) or the visual analogue scale (VAS). This limitation precludes the ability to assess and evaluate cardiac pain comprehensively and identify the various dimensions of an acute cardiac pain experience. Therefore, the purpose of this secondary analysis was to examine the sensory-discriminative, motivational-affective and cognitive-evaluative dimensions of an ACS-related pain episode. 


\section{Methods}

\subsection{Subjects/Setting}

Secondary analysis was conducted on 121 ACS adult men and women, admitted to a community ED in south-eastern Ontario, Canada, for report of cardiac pain during an ACS episode. The parent study examined the relationship of pain management practices and nurses' pain knowledge and attitudes on ACS patients cardiac pain intensity and level of state anxiety, in a descriptive-correlational, repeated measures design over the first 8 hours of an ED admission [11]. Of note: this study was conducted prior to the initiation of CODE STEMI protocol within South-East-Ontario, wherein patients would routinely wait 24 - 36 hours before transfer to a tertiary cardiac center for diagnostic angiogram [12] [13].

Patients were included if they met the following inclusion criteria:1) diagnosed with unstable angina (UA) or non-ST-elevation myocardial infarction (NSTEMI); 2) Canadian Triage Acuity Scale Score of 2 (indicative of an emergent status and required assessment within 15 minutes of emergency department (ED) triage) [14]; and 3) able to speak, read and comprehend English. Additionally, eligibility criteria included cardiac chest pain of more than 20 minutes in duration and/or pain described using angina equivalent pain descriptors (i.e. nausea, vomiting, shortness of breath, dizziness, fatigue, chest tightness, syncope, diaphoresis), and electrocardiogram changes (ST depression or elevation) in one or more leads. Patients were excluded if they were diagnosed with ST-elevation myocardial infarction [STEMI] (emergent-requiring immediate triage and transfer within 2 to 6 hours for reperfusion percutaneous coronary intervention; had recent sternotomy for coronary artery bypass grafting, or valve replacement (as it may confound the acute pain intensity outcome, should they develop persistent post-operative pain); or if they were unable to consent verbally and in writing.

\subsection{Data Collection}

After initial triage and stabilization, registered nurses (RNs) working in the ED as team leaders, acted as recruitment champions identified potential patient participants to the primary investigator [PI] (SOM). Eligibility was confirmed by the PI; patients were approached and provided with a verbal and written explanation of the study. Once the consent was signed, demographic data were completed at baseline with follow-up every two hours for a total of 4 repeated measurements of cardiac pain intensity in the moment "now" and the "worst cardiac pain intensity in the previous 2 hours from follow-up". In order to capture a more thorough and comprehensive understanding of cardiac pain, at the 4-hour mark, cardiac pain was measured using the McGill Pain Questionnaire-Short-form (MPQ-SF) [2]. At the conclusion of the 8-hour study, participants' health care records were reviewed to complete and verify accurate documentation of the sociodemographic, medical history and clinical variable data.

\subsection{Measurement Instruments}

Numeric Rating Scale: Cardiac pain intensity was measured every two hours from 
baseline with the numeric rating scale (NRS). This 11-point numeric scale measures the intensity of the pain where zero indicates no pain, 1 - 3 mild, 4 - 6 moderate and $7-10$ severe cardiac pain intensity. The NRS has well established reliability, construct validity, and concurrent validity in cardiovascular, non-ED and ED populations [2] [15] [16] [17] [18] [19]. Concurrent validity has been evidenced by strong correlations between the NRS and visual analog scale (VAS) [15].

McGill Pain Questionnaire-Short Form (MPQ-SF) [2]: The MPQ-SF is a comprehensive pain measure with well-established reliability, validity, sensitivity, and discriminative capacity in both acute and chronic pain populations [20] [21] [22] [23] [24]. The MPQ-SF is a multidimensional pain inventory and includes items that assess the three psychological dimensions of the pain experience: sensory-discriminative, motivational-affective and cognitive-evaluative [2]. The three dimensions of pain are derived from a list of pain descriptors including a pain rating index (PRI), the visual analogue scale (VAS), and the present pain intensity (PPI) [2] [25]. The PRI is based on the rank value of words chosen among 4 subscales that describe sensory, affective, evaluative, and miscellaneous aspects of pain. The PRI of 15 verbal descriptors rated on a 4-point intensity scale (each value of descriptor is based on its position in the word set) were summed to obtain scores for sensory (1 - 11) and affective (12 - 15) quality of pain [2] [25].

Overall pain intensity was measured by the MPQ-SF present pain intensity (PPI). The PPI is the number-word combination chosen as the indicator of the overall pain intensity with a range of 0 to 5 . Reported alpha coefficients for the PRI subscales are (0.78) sensory, (0.71) affective, (0.47) evaluative, and (0.82) for the total PRI. Correlation coefficients between PPI and PRI subscales were (0.90) sensory, (0.82) affective, (0.96) evaluative and (0.92) miscellaneous. For the purpose of the parent study, the VAS in the MPQ-SF was replaced with the NRS, an equally valid and reliable self-report pain measurement tool [21].

\subsection{Data Analysis}

SAS software 9.2 was used to analyse these data (SAS, 2009) [26]. A sample of 150 was projected as necessary to detect correlations of medium size (0.3) with $90 \%$ power and a two-sided alpha (0.05), accounting for a design effect of at least three measurements per patient and multiple patients per nurse and $25 \%$ loss to follow up. Descriptive statistics were computed (means and standard deviations for continuous variables, frequencies and proportions for categorical variables) for pre-hospital, baseline sociodemographic and clinical characteristics and the sensory and affective descriptions of cardiac pain.

\section{Results}

Acute Coronary Syndrome Participants: A total of 191 potential participants were approached to participate in the study. Of those, 121 consented and were enrolled; 70 were excluded ( 47 did not meet inclusion criteria and 23 people refused). The acceptance rate was $63 \%$. Attrition rate was conceptualized as those patients who did not have at least one repeated measure opportunity beyond baseline. Four 
per cent were lost to follow-up as 5 ACS patients did not complete at least one repeated measure. Table 1 and Table 2 provide descriptions of the pre-hospital profile and sociodemographic characteristics of the ACS sample, respectively. Women and men had equal representation, mean age was $67.6 \pm 13$ years, $66.1 \%$ $(\mathrm{n}=81)$ were married, with $60.3 \%$ of the sample were retired $(\mathrm{n}=73)$ and $97.5 \%$ were Caucasian. Most reported at least one co-morbidity (i.e., hypertension 61.2\%; hyperlipidemia 58.7\%). Of the 121 enrolled, 59.5\% $(\mathrm{n}=72)$ were diagnosed with UA and $40.5 \%(n=49)$ with NSTEMI.

Cardiac Pain Intensity: Over the 8 hours of the study, patients reported cardiac pain in the moment "Now" and the "Worst pain in the last two hours from follow up" in the mild range. At baseline, the mean chest pain score (NRS) was $2.0 \pm 2.4$. Over five consecutive measurement times, at two hour increments, cardiac pain intensity "now" ranged from $0.63 \pm 1.6$ to $1.1 \pm 2.1$ and the mean worst pain in the previous 2 hours ranged from $1.1 \pm 2.2$ to $2.4 \pm 2.7$.

The Present Pain Intensity Scale, contained in the MPQ-SF, measured pain intensity at the four-hour mark rating pain of $0-5$ with $0=$ no pain, $1=$ mild pain, $2=$ discomforting pain, $3=$ distressing pain, $4=$ horrible pain and $5=\mathrm{ex}-$ cruciating pain. Sixty-six percent of the sample described their pain as discomforting and distressing which equates with a moderate level of pain. For $26 \%$ of the ACS patients, global chest pain at four hours into an acute ED admission was

Table 1. Sociodemographic characteristics of ACS sample (n-121).

\begin{tabular}{|c|c|c|c|}
\hline Demographics & Level & & \\
\hline \multirow[t]{2}{*}{ Mean Age, y (SD) } & $\mathrm{M} / \mathrm{F}$ & 67.6 & (13) \\
\hline & & $\mathrm{n}$ & $(\%)$ \\
\hline \multirow{3}{*}{ Sex } & Female & 58 & $(47.9)$ \\
\hline & Male & 63 & $(52.1)$ \\
\hline & Single & 16 & $(13.2)$ \\
\hline \multirow[t]{4}{*}{ Marital Status } & Married & 81 & $(66.1)$ \\
\hline & Widowed & 25 & $(20.7)$ \\
\hline & Full time & 21 & $(17.4)$ \\
\hline & Part time & 5 & $(4.1)$ \\
\hline \multirow[t]{4}{*}{ Employment Status } & Retired & 73 & $(60.3)$ \\
\hline & Unemployed/Disability & 3 & $(2.5)$ \\
\hline & Other & 19 & $(15.7)$ \\
\hline & Less than High School & 43 & $(35.5)$ \\
\hline \multirow[t]{2}{*}{ Education } & High School & 38 & $(31.4)$ \\
\hline & College/University & 40 & $(31.7)$ \\
\hline \multirow{2}{*}{ Racial Group } & Caucasian & 118 & $(97.5)$ \\
\hline & Other & 3 & $(2.4)$ \\
\hline \multirow{3}{*}{ Smoker } & Never smoked & 30 & $(24.8)$ \\
\hline & Non-smoker for one year or longer & 70 & $(57.9)$ \\
\hline & Current smoker & 21 & $(17.3)$ \\
\hline \multirow{2}{*}{ ACS } & Unstable Angina & 72 & $(59.5)$ \\
\hline & Non-STEMI & 49 & $(40.5)$ \\
\hline
\end{tabular}

Note: $\mathrm{M}=$ Mean; Other $=$ Self Employed, $\mathrm{SD}=$ Standard Deviation. 
Table 2. Pre-hospital profile and clinical characteristics of ACS participants.

\begin{tabular}{|c|c|c|}
\hline Characteristic & $\mathrm{n}$ & $\%$ \\
\hline \multicolumn{3}{|l|}{ Pre-Admission Profile } \\
\hline Worst Chest Pain Severity 2 hours pre-hospital admission $M(\mathrm{SD})$ & 6.4 & $(2.6)$ \\
\hline \multicolumn{3}{|l|}{ Medications } \\
\hline ACE inhibitor/Angiotension receptor blockers/Renin Inhibitor & 61 & 50.8 \\
\hline Anticoagulant/Antiplatelets & 90 & 75.6 \\
\hline Anti-arrhythmic & 13 & 10.8 \\
\hline$\beta$-Blockers & 70 & 58.3 \\
\hline CA/NA Channel Blockers & 12 & 10 \\
\hline Lipid Lowering Agents & 71 & 59.2 \\
\hline Diuretic & 37 & 30.8 \\
\hline Analgesic/Opioids & 22 & 18.3 \\
\hline Other (proton pump inhibitor, $\mathrm{H}_{2}$ receptor antagonists, insulin/oral diabetic agents) & 23 & 19.5 \\
\hline \multicolumn{3}{|l|}{ Medical History } \\
\hline Diabetes & 31 & 25.8 \\
\hline Hypertension & 74 & 61.2 \\
\hline Heart Failure & 11 & 9.1 \\
\hline COPD & 28 & 23.1 \\
\hline Peptic Ulcer/Esophageal Reflux & 34 & 28.1 \\
\hline Liver Disease & 8 & 6.6 \\
\hline Thyroid Condition & 18 & 14.9 \\
\hline Persistent Pain Syndrome & 49 & 40.5 \\
\hline Hyperlipidemia & 71 & 58.7 \\
\hline
\end{tabular}

Note: $\mathrm{ACE}=$ Angiotension Converting Enzyme, $\mathrm{ACS}=$ Acute Coronary Syndrome, $\beta=\mathrm{Beta}, \mathrm{CA}=\mathrm{Cal}-$ cium, $\mathrm{COPD}=$ Chronic Obstructive Lung Disease, $\mathrm{H}_{2}=$ Histamine Parietal Cell Receptor, $\mathrm{NA}=$ Sodium, $\mathrm{M}$ $=$ Mean, $\mathrm{SD}=$ Standard Deviation.

reported as horrible or excruciating; this corresponds to severe pain intensity levels (See Table 3).

Sensory and Affective Descriptors of Cardiac Pain: Men and women in this study described their cardiac pain using a mixture of neuropathic (indicative of nerve damage-chronic pain) and nociceptive (related to acute injury) pain qualities early during the first eight hours of an emergent ACS episode. The sensory descriptors included: "heavy" 57.3\% ( $\mathrm{n}=63)$, "cramping" 34.6\% $(\mathrm{n}=38)$, "sharp" $30 \%(\mathrm{n}=33)$, "stabbing" $21.8 \%(\mathrm{n}=24)$; all acute pain descriptors. Patients described their pain as "aching" $35.4 \%(\mathrm{n}=39)$, "tender" $18.1 \%(\mathrm{n}=20)$, "throbbing" $14.6 \%(n=16)$ indicating both acute and chronic pain qualities. Additionally, patients described their episode of acute chest pain using neuropathic pain descriptors which included: "gnawing" 44.5\% ( $\mathrm{n}=49)$, "hot-burning" $27.2 \%(\mathrm{n}=$ 30 ), and "shooting" 23.7\% ( $\mathrm{n}=26)$ (See Table 4) for sensory descriptors reported by ACS participants. More than $50 \%$ of the sample used affective descriptors to 
describe their ACS-related chest pain. Fifty-five point five percent $(n=61)$ of patients described their pain experience as tiring and exhausting, a mixture of acute and persistent pain quality descriptors. Additional affective pain quality descriptors used were: punishing and cruel (20\%), sickening (28.2\%), with $48.3 \%$ of this ACS sample described their acute pain as fearful in nature.

\section{Discussion}

Qualities of ACS-related Cardiac Pain: This study sought to provide a thorough and comprehensive description of acute cardiac pain observed during an emergent

Table 3. Global pain rating (present pain intensity [PPI]) of chest pain at 4 hours post ACS admission $(n=110)$.

\begin{tabular}{ccc}
\hline & \multicolumn{3}{c}{ ACS Patients } \\
\cline { 2 - 3 } Descriptor & $\mathrm{n}$ & $(\%)$ \\
\hline No Pain $^{\wedge}$ & 5 & $(4.5)$ \\
Mild $^{\wedge}$ & 6 & $(37.3)$ \\
Discomforting $^{+}$ & 41 & $(29.1)$ \\
Distressing $^{+}$ & 32 & $(15.5)$ \\
Horrible $^{\star}$ & 17 & $(8.2)$ \\
Excruciating
\end{tabular}

Note: ${ }^{\wedge}=$ mild pain, ${ }^{+}=$moderate pain, ${ }^{*}=$ severe pain

Table 4. Descriptors of mild-severe chest pain by ACS patients (MPQ-SF-PRI) at 4 hours post ACS admission.

\begin{tabular}{|c|c|c|}
\hline \multirow{2}{*}{ Descriptor } & \multicolumn{2}{|c|}{ ACS Patients $(\mathrm{n}=110)$} \\
\hline & $\mathrm{n}$ & $(\%)$ \\
\hline \multicolumn{3}{|l|}{ Sensory } \\
\hline Throbbing ${ }^{*+}$ & 16 & $(14.6)$ \\
\hline Shooting $^{+}$ & 26 & $(23.7)$ \\
\hline Stabbing* & 24 & $(21.8)$ \\
\hline Sharp* & 33 & $(30)$ \\
\hline Cramping* & 38 & $(34.6)$ \\
\hline Gnawing $^{+}$ & 49 & $(44.5)$ \\
\hline Hot-burning $^{+}$ & 30 & $(27.2)$ \\
\hline Aching $^{*+}$ & 39 & $(35.4)$ \\
\hline Heavy* & 63 & $(57.3)$ \\
\hline Tender ${ }^{*+}$ & 20 & $(18.1)$ \\
\hline Splitting & 8 & $(7.2)$ \\
\hline \multicolumn{3}{|l|}{ Affective } \\
\hline Tiring-Exhausting ${ }^{+}$ & 61 & $(55.5)$ \\
\hline Sickening & 31 & $(28.2)$ \\
\hline Fearful & 53 & $(48.3)$ \\
\hline Punishing-Cruel $^{+}$ & 22 & (20) \\
\hline
\end{tabular}

Note: ${ }^{\star}$ May indicate nociceptive pain, ${ }^{+}$May indicate neuropathic pain. 
episode of ACS. Overall, mild pain intensity scores were observed over time in the current study. This result may be related to the effective and timely pain management provided by skilled emergency nurses reported in the parent study [11]. Reports of mild pain may also be related to the pathophysiology of clot formation common to the two forms of ACS included in the study: unstable angina (UA) and (NSTEMI). Two kinds of obstructive thrombi can form causing myocardial ischemia; a white clot or a red clot. Characteristically, UA and NSTEMI develop platelet rich white clots in areas of high shear stress that only partially occlude the artery [27] [28] [29] [30]. Sixty percent of patients in the present study were diagnosed with UA and $40 \%$ with NTSEMI. Therefore, it was not unexpected that those with NSTEMI and UA would, perhaps, report lower NRS pain intensity ratings. NSTEMI is characterized by multiple small areas of necrosis at varying different ages [31]. Typically, patients admitted with NSTEMI do not report as severe pain compared to STEMI patients [32]. Once death of myocardial tissue occurs, typically, pain recedes and is reported in the moderate to mild pain ranges (0 - 3; 4 - 6; NRS 0/10) [32]. Conversely, STEMI patients develop red fibrin rich clots that totally occlude the vessel and cause a singular or homogenous entity; that is, necrosis of myocardial tissue occurs all at the same time [33]. This event is described as extremely painful and would result in greater pain intensity scores, not observed in the current study. Data in this study captured a relatively stable sample of ACS patients with NSTEMI and UA and not the emergent trajectory of STEMI-related cardiac ischemic event. It is unknown whether pain intensity scores would be reported within the moderate to severe range by STEMI patients compared with the current study's sample.

Mild cardiac pain intensity scores may also be related to a first time or recurrent ACS event. Given the increased prevalence of repeated/cumulative ACS events [34], it may be plausible that the observed mild NRS intensities may be attributed to those with repeated ACS events. In this study, first time or repetitive ACS events were not captured. It is not clear if increased myocardial scar tissue from past myocardial insult, injury, or death of tissue may have prevented transmission of noxious input, thereby altering pain perception. Furthermore, we currently do not know if those with repeated ACS events are more likely to develop persistent pain and would describe their acute pain with more neuropathic pain qualities rather than acute injury descriptions. This would require a more in-depth exploration. To date, no studies were found that examined first time or repeated ACS event and cardiac pain intensity. However, in emergency settings portable echocardiography is typically used to evaluate myocardial wall thickness, motion at rest and aids in differentiation of UA and NSTEMI [35] and would be a useful adjunct to examine pain intensity differences, stratifying first time and repetitive ACS episodes among UA, NSTEMI and STEMI patients.

A third explanation for mild cardiac pain intensity scores found in this study may also relate to the percentage of men and women who had diabetes as comorbidity. Over $25 \%$ of patient participants $(n=31)$ had documented diabetes mellitus (DM). Evidence indicates that people with DM, over time, may develop 
autonomic neuropathy and may not exhibit or report severe cardiac pain intensity [7] [36] [37] [38] [39]. Up to 70\% of people with DM have some form of diabetic neuropathy [40]. Mild cardiac pain intensity found in this study in DM patients is an important finding and resonates with others who have reported atypical and/or mild pain intensity within the diabetic cardiac population [41] [42]. For example, in a descriptive-cross-sectional study, MacKenzie and Neibert examined ACS symptoms in women with and without DM [42]. Included in the sample were 64 women, (32 with DM and 32 without DM), and diagnosed with either UA or acute myocardial infarction (AMI). Patients with DM and UA or AMI were more likely to report mild sternal chest pain compared to non-diabetics $(p=0.04)$. Similarly, in Cŭ lić et als., (2002) [41] study, for the entire ACS sample ( $n=1996)$, [42\% women], admitted to the coronary care unit for first time AMI, found both men and women reported less pain severity with AMI $(\mathrm{OR}=1.31$, CI [1.11 to 1.66$])$ than those without DM. It was not clear whether diabetic neuropathy was controlled for in their statistical analyses.

A more nuanced examination of cardiac-related pain in ACS patients with diabetes is required. The examination of pain should include a comprehensive measure, such as the McGill Pain Questionnaire, to provide a thorough description of the subjective, sensory-discriminative, cognitive-evaluative, affectivemotivational and miscellaneous aspects [2] and range of ACS-related pain symptoms. In addition to stratification of DM-ACS patients and ACS differentiation, it would be important to expand pain assessment and test participants with use of quantitative sensory testing to determine prevalence of DM neuropathy [40]. Moreover, those identified with DM-related neuropathy would be controlled for in future regression model analyses.

Sensory and Affective Qualities of ACS Pain: Examining cardiac pain utilizing a uni-dimensional pain measure limits the ability to comprehensively describe the variable qualities of the individual's ACS-related pain experience. All ACS patients were therefore asked to describe their cardiac pain using the McGill Pain Questionnaire-Short Form (MPQ-SF) [2] at the 4-hour mark during the study. Of the patient sample, men and women chose descriptors depicting chest pain as having characteristics of nociceptive and neuropathic pain qualities early in the first hours of an ED admission. Others have found similar results, McGillion et al., (2012) [43] in the EXPLORE study reported that their ACS sample $(n=110)$ post percutaneous coronary intervention $(\mathrm{PCI})$, described cardiac pain with an admixture of neuropathic and nociceptive descriptors for pain at three and six months post PCI [43]. Results of the current study may be related to the inclusion criteria of an ACS sample that was composed of patients with either UA or NSTEMI. It is unclear whether patients experienced a first time or repeated ACS event that may have explained the variable pain qualities reported. We can only speculate as to whether ACS patients who were admitted with a repeated ACS event would have developed neuropathic pain over time with repeated ischemic events. This requires a longer follow up time period with a more inclusive sample of UA, NSTEMI and STEMI ACS patients in the future. 
Understanding recent advancements in pain neuropathophysiology may further explain the sensory and affective pain qualities reported by patients in this study. Given the complexity of an individual pain presentation, complicated by either concurrent co-morbidities that may impact (alter) pain perception, coupled with an initial or reoccurring ACS episode, it may be best explained from what is known based on pain science. Foreman and others have elegantly explained the indirect relationship between myocardial ischemia and perceived chest pain intensity [3] [4] [5] [6] [7]. Current basic science and clinical evidence point to the variability of cardiac pain perception wherein chest pain can occur in the absence of myocardial ischemia, and, conversely, ischemic episodes can be painless, [44] [49] typically observed in clinical practice from individuals with documented diabetes.

Men and women who have repeated angina and/or multiple cardiac events may describe their acute pain using neuropathic or nerve-related descriptors because acute cardiac pain experienced over time can lead to maladaptive processes that lead to the development of chronic or persistent forms of cardiac pain. Ongoing or repeated pain episodes cause negative changes in the nervous system such as maladaptive anaerobic glycolysis, tissue lactate production, accumulation of catabolites, and potassium efflux into the extracellular space [3] [4] [5] [6]. Acute pain, repeated episodes lead to pathological changes at the peripheral and central nervous system; these changes are collectively known as central sensitization [3] [4] [5] [6]. Sensitization of the nervous system leads to different maladaptive forms of pain perception: hyperalgesia (increase pain sensitivity), hyperpathia (augmentation of normal pain duration) and increased intensity of the pain [3] [4] [5] [6]. In all cases, transition from acute pain to chronic or persistent cardiac pain, is in part, a function of sensitization that occurs from prolonged periods or repetitive episodes of acute cardiac pain that involves a transition phase by virtue of these pathological mechanisms. This may explain why our sample reported both acute and chronic pain qualities during an acute ACS event.

In summary, patients in the current study reported mild (NRS 0 - 3) cardiac pain intensity scores over the initial 8 hours of an ACS-related event. Variable pain quality descriptors used to describe acute cardiac pain in this ACS sample were a combination of nociceptive (acute injury) and neuropathic (nerve damagepersistent pain). Possible explanations for this result have been discussed as attributed to, (a) differences in ACS sample, (b) pathogenesis of clot formation, (c) first versus repeated ACS event, and (d) diabetes as comorbidity.

Limitations: This study was conducted in a single ED setting with predominately a homogeneous Caucasian sample, with limited enrollment of only UA and NSTEMI ACS patients. Therefore, areas for future research include, 1) a larger, multisite study, applying a stratified analysis approach that would include all ACS differentiation examining pain management practices and cardiac pain intensity, 2) a larger study that would examine differences in cardiac pain presentation, in all ACS patients, with use of portable echocardiography, stratifying for first time and repeated ACS event, and 3) a larger, multisite study that thoroughly examines the diabetic-ACS pain presentation with use of quantitative 
sensory testing in order to determine the prevalence of diabetic neuropathy. Controlling for diabetic neuropathy may provide an in-depth description of ACS pain presentations within the diabetic context.

\section{Conclusion}

The aim of this sub-analysis was to provide a comprehensive examination of the sensory-discriminative, motivational-affective and cognitive-evaluative dimensions of cardiac pain not previously captured or documented in the acute hours of an emergent ACS event. Sixty-six percent of the sample described cardiac pain as acute injury "heavy, cramping, stabbing, and sharp" (nociceptive pain). Others reported nerve-related damage pain qualities, "gnawing, hot-burning, shooting" (neuropathic pain) and a combination of acute and chronic pain qualities "aching, tender and throbbing". Further investigations are warranted to clearly describe the individual complex cardiac pain presentations as it relates to ACS designation, singular or repeated ACS event and level of co-morbidity.

\section{Acknowledgements}

Authors would like to thank the patients and ED staff who participated in the study and to Dr. S. Nelson and S. Clarke for their invaluable assistance with this study.

\section{Financial Support}

S. O'Keefe-McCarthy's work was supported by the Canadian Cardiovascular Nurse Scientists FUTURE Program (CIHR/HSFC), Canadian Pain Society (CPS) Trainee Research Grant; CPS-Nursing Education and Research Award; Registered Nurses Foundation of Ontario; Ontario Graduate Scholarship; Lawrence S. Bloomberg Faculty of Nursing Fellowship; Canadian Association of University Teachers-J.H. Stewart-Reid Memorial Fellowship; University of Toronto Centre for the Study of Pain-Clinical Pain Scientist Scholarship; Registered Nurses Association of Ontario-Nursing Research Interest Group-Graduate Scholarship; Royal Bank of Canada Chair in Cardiovascular Nursing-Graduate Student-Stipend University Health Network, Toronto, Ontario, the University of TorontoDoctoral Dissertation Completion Award and the Sigma Theta Tau International Nursing Society-Rising Stars Scholarship.

\section{References}

[1] O’Keefe-McCarthy, S., McGillion, M., Nelson, S., et al. (2014) Acute Coronary Syndrome Pain and Anxiety in a Rural Emergency Department-Patient and Nurse Perspectives. Canadian Journal of Nursing Research, 46, 80-100.

[2] Melzack, R. (1975) The McGill Pain Questionnaire: Major Properties and Scoring Methods. Pain, 1, 277-299. https://doi.org/10.1016/0304-3959(75)90044-5

[3] Basbaum, A., Bushnell, C. and Devor, M. (2005) Pain: Basic Mechanisms. In: Justins, D.M., Ed., Pain 2005: An Updated Review, IASP Press, Seattle, 3-9.

[4] Foreman, R.D. and Qin, C. (2009) Neuromodulation of Cardiac Pain and Cerebral 
Vasculature: Neural Mechanisms. Cleveland Clinical Journal of Medicine, 76, S75S79. https://doi.org/10.3949/ccjm.76.s2.15

[5] Foreman, R.D. (1999) Mechanisms of Cardiac Pain. Annual Review of Physiology, 61, 143-167. https://doi.org/10.1146/annurev.physiol.61.1.143

[6] Procacci, P., Zoppi, M. and Maresca, M. (2003) Deep Visceral Pain: Heart, Vascular, and Haemopathic Pain. In: Melzack, R. and Wall, P.D., Eds., Handbook of Pain Management. A Clinical Companion to Wall s and Melzack's Text Book of Pain, Churchill Livingstone, Toronto, 121-134.

https://doi.org/10.1016/B978-0-443-07201-7.50013-8

[7] Rosen, S.D. (2012) From the Heart to Brain: The Genesis and Processing of Cardiac Pain. Canadian Journal of Cardiology, 28, S7-S19.

https://doi.org/10.1016/j.cjca.2011.09.010

[8] Eftekhari, H., Bukjarvoich, I., Aziz, E. and Hong, M.K. (2008) Epidemiology and Pathophysiology of Acute Coronary Syndrome. In: Hong, M.K. and Herzog, E., Eds., Acute Coronary Syndrome Multidisciplinary and Pathway-Based Approach, Springer, London, 25-36.

[9] Bassand, J.P., Hamm, C.W., Ardissino, D., et al. (2007) Guidelines for the Treatment and Diagnosis of Non ST-Segment Elevation Acute Coronary Syndrome. European Heart Journal, 28, 1589-1660.

[10] Melzack, R. (2001) Pain and the Neuromatrix in the Brain. Journal of Dental Education, 655, 1378-1382.

[11] O’Keefe-McCarthy, S., McGillion, M., Clarke, S. and McFetridge-Durdle, J. (2014) Pain and Anxiety in Rural Acute Coronary Syndrome Patients Awaiting Diagnostic Cardiac Catheterization. Journal of Cardiovascular Nursing, 30, 546-557.

[12] Cantor, W.J., Fitchett, D., Bourgundvaag, B., et al. (2008) Rationale and Design of the Trial of Routine Angioplasty and Stenting after Fibrinolysis to Enhance Reperfusion in Acute Myocardial Infarction (TRANSFER-AMI). American Heart Journal, 155, 19-25. https://doi.org/10.1016/j.ahj.2007.08.025

[13] Cantor, W.J., Fitchett, D., Bourgundvaag, B., et al. (2009) Routine Early Angioplasty after Fibrinolysis for Acute Myocardial Infarction. The New England Journal of Medicine, 360, 2705-2718. https://doi.org/10.1056/NEJMoa0808276

[14] Murray, M., Bullard, M. and Grafstein, E. (2004) Revision of the Canadian Emergency Department Triage Acuity Scale: Implementation of Guidelines. Canadian Journal of Emergency Medicine, 6, 421-427.

[15] Downie, W.W., Leatham, P.A., Rhind, V.M., et al. (1978) Studies with Pain Rating Scales. Annals of the Rheumatic Diseases, 37, 378-381. https://doi.org/10.1136/ard.37.4.378

[16] Jensen, M.P., Karoly, P., O’Riordan, E.F., et al. (1989) The Subjective Experience of Acute Pain. The Clinical Journal of Pain, 5, 153-159. https://doi.org/10.1097/00002508-198906000-00005

[17] Jensen, M.P., Karoly, P. and Braver, S. (1986) The Measurement of Clinical Pain Intensity: A Comparison of Six Methods. Pain, 27, 117-126. https://doi.org/10.1016/0304-3959(86)90228-9

[18] Puntillo, K. and Neighbor, M.L. (1997) Two Methods of Assessing Pain Intensity in English Speaking and Spanish-Speaking Emergency Department Patients. Journal of Emergency Nursing, 23, 597-601. https://doi.org/10.1016/S0099-1767(97)90276-2

[19] Puntillo, K.A. and Weiss, S.J. (1994) Pain: Its Mediators and Associated Morbidity in Critically Ill Cardiovascular Surgical Patients. Nursing Research, 43, 31-36. https://doi.org/10.1097/00006199-199401000-00006 
[20] Melzack, R. and Wall, P. (1982) The Challenge of Pain. 2nd Edition, Penguin Books, New York.

[21] Melzack, R. and Dennis, S. (1978) Neurophysiological Foundation of Pain. In: Steinbeach, R., Ed., The Psychology of Pain, Raven Press, New York, 1-26.

[22] Melzack, R. (1987) The Short-Form McGill Pain Questionnaire. Pain, 30, 191-197. https://doi.org/10.1016/0304-3959(87)91074-8

[23] Melzack, R. (1999) Pain-An Overview. Acta Anaesthesiologica Scandinavica, 43, 880-884. https://doi.org/10.1034/j.1399-6576.1999.430903.x

[24] Melzack, R. and Katz, J. (2001) The McGill Pain Questionnaire: Appraisal and Current Status. In: Turk, D.C. and Melzack, R., Eds., Handbook of Pain Assessment, 2nd Edition, Guilford Press, New York.

[25] Turk, D.C., Rudy, T.E. and Salovey, P. (1985) The McGill Pain Questionnaire Reconsidered: Confirming the Factor Structure and Examining Appropriate Uses. Pain, 21, 385-397. https://doi.org/10.1016/0304-3959(85)90167-8

[26] SAS Software Version 9.2. SAS Institute Inc., SAS Campus Drive, Cary, 27153.

[27] Mizuno, K., Satumo, K., Miyamoto, A., et al. (1992) Angioscopic Evaluation of Coronary Artery Thrombi in Acute Coronary Syndromes. The New England Journal of Medicine, 326, 287-291. https://doi.org/10.1056/NEJM199201303260502

[28] Sherman, C.T., Litvack, F., Grundfest, W., et al. (1986) Coronary Angioscopy in Patients with Unstable Angina Pectoris. The New England Journal of Medicine, 315, 913-919. https://doi.org/10.1056/NEJM198610093151501

[29] Sullivan, E., Kearney, M., Isner, J.M., et al. (1994) Pathology of Unstable Angina: Analysis of Biopsies Obtained by Directional Coronary Atherectomy. Journal of Thrombosis and Thrombolysis, 1, 63-71. https://doi.org/10.1007/BF01061998

[30] The TIMI IIIA Investigators (1993) Early Effects of Tissue-Type Plasminogen Activator Added to Conventional Therapy on the Culprit Lesion in Patients Presenting with Ischemic Cardiac Pain at Rest Results of the Thrombolysis in Myocardial Ischemia (TIMI IIIA) Trial. Circulation, 87, 38-52.

https://doi.org/10.1161/01.CIR.87.1.38

[31] Davies, M.J. (2000) Coronary Disease: The Pathophysiology of Acute Coronary Syndromes. Heart, 83, 361-366. https://doi.org/10.1136/heart.83.3.361

[32] Thuresson, M., Jarlöv, M.B., Lindahl, B., et al. (2005) Symptoms and Type of Symptom Onset in Acute Coronary Syndrome in Relation to ST Elevation, Sex, Age, and a History of Diabetes. American Heart Journal, 150, 234-242.

https://doi.org/10.1016/j.ahj.2004.08.035

[33] DeWood, M.A., Spores, J., Notske, R., et al. (1980) Prevalence of Total Coronary Occlusion during the Early Hours of Transmural Myocardial Infarction. The New England Journal of Medicine, 303, 897-902. https://doi.org/10.1056/NEJM198010163031601

[34] Rosamond, W., Flegal, K., Furie, K., et al. (2008) Heart Disease and Stroke Statistics-2008 Update: A Report from the American Heart Association Statistics Committee and Stroke Statistics Subcommittee. Circulation, 117, e25-e146. https://doi.org/10.1161/CIRCULATIONAHA.107.187998

[35] Thygesen, K., Alpert, J.S., White, H.D., et al. (2007) Universal Definition of Myocardial Infarction. European Heart Journal, 28, 2525-2538. https://doi.org/10.1093/eurheartj/ehm355

[36] Braun, L.T. (2006) Cardiovascular Disease: Strategies for Risk Assessment and Modification. Journal of Cardiovascular Nursing, 6, S20-S42. https://doi.org/10.1097/00005082-200611001-00004 
[37] Hartmann, A., Schlottog, B., Jungmann, E., et al. (1993) Somatic Pain Threshold and Reactive Hyperemia in Autonomic Diabetic Neuropathy and Silent Myocardial Ischemia. International Journal of Cardiology, 42, 121-127. https://doi.org/10.1016/0167-5273(93)90081-Q

[38] Page, M. and Watkins, P. (1978) Cardiorespiratory Arrest and Diabetic Autonomic Neuropathy. The Lancet, 1, 14. https://doi.org/10.1016/S0140-6736(78)90360-4

[39] Teoh, M., Lalondrelle, S., Roughton, M., et al. (2007) Acute Coronary Syndromes and Their Presentation in Asian and Caucasian Patients in Britain. Heart, 93, 183 188. https://doi.org/10.1136/hrt.2006.091900

[40] Maser, R.E., Neilson, V.K., Bass, E.B., et al. (1989) Measuring Diabetic Neuropathy Assessment and Comparison of Clinical Examination and Quantitative Sensory Testing. Diabetic Care, 12, 270-275. https://doi.org/10.2337/diacare.12.4.270

[41] Čulić, V., Eterović, D., Mirić, D. and Silić, N. (2002) Symptom Presentation of Acute Myocardial Infarction: Influence of Sex, Age, and Risk Factors. American Heart Journal, 144, 1012-1017. https://doi.org/10.1067/mhj.2002.125625

[42] MacKenzie, G. and Neibert, M.B. (2001) Diabetes and Myocardial Infarction or Unstable Angina: Do Patients with Diabetes Report Pain and Symptoms Differently than Patients without Diabetes? Canadian Journal of Cardiovascular Nursing, 11, 25-34.

[43] McGillion, M., Arthur, H.M., Cook, A., et al. (2012) Nonischemic Chest Pain Following Successful PCI at a Regional Referral Centre in Southern Ontario. Canadian Journal of Cardiology, 28, S60-S80. https://doi.org/10.1016/j.cjca.2011.10.017

[44] Cannon, R.O. (1995) Cardiac Pain. In: Gebhard, G.F., Ed., Progress in Pain Research and Management, Vol. 5, IASP Press, Seattle, 373-389.

[45] Deedwania, P.C. and Carbajal, E.V. (1990) Silent Ischemia during Daily Life Is an Independent Predictor of Mortality in Stable Angina. Circulation, 81, 748-756. https://doi.org/10.1161/01.CIR.81.3.748

[46] Malliani, A. (1995) The Conceptualization of Cardiac Pain as a Non-Specific and Unreliable Alarm System. In: Gebharet, G.F., Ed., Visceral Pain, IASP Press, Seattle, 63-74.

[47] Malliani, A. (1986) The Elusive Link between Transient Myocardial Ischemia and Pain. Circulation, 73, 201-204. https://doi.org/10.1161/01.CIR.73.2.201

[48] Maseri, A., Chierchia, S., Davies, G. and Glazier, J. (1985) Mechanisms of Ischemic Cardiac Pain and Silent Myocardial Ischemia. American Journal of Medicine, 79, 7 11. https://doi.org/10.1016/0002-9343(85)90487-5

[49] Pepine, C.J. (1996) Does the Brain Know When the Heart Is Ischemic? Annals of Internal Medicine, 124, 1006-1008.

https://doi.org/10.7326/0003-4819-124-11-199606010-00009 
Submit or recommend next manuscript to SCIRP and we will provide best service for you:

Accepting pre-submission inquiries through Email, Facebook, LinkedIn, Twitter, etc. A wide selection of journals (inclusive of 9 subjects, more than 200 journals)

Providing 24-hour high-quality service

User-friendly online submission system

Fair and swift peer-review system

Efficient typesetting and proofreading procedure

Display of the result of downloads and visits, as well as the number of cited articles Maximum dissemination of your research work

Submit your manuscript at: http://papersubmission.scirp.org/

Or contact ojn@scirp.org 